\title{
UTILIZATION OF AQUEOUS, METHANOL AND CHLOROFORM EXTRACTS OF LOCAL PLANTS- IXORA COCCINEA AND HIBISCUS SABDARRIFFA (ZOBO) FROM ABAKALIKI AS FABRIC DYES
}

\author{
${ }^{1 * N w o k o n k w o, ~ D . C ; ~}{ }^{2}$ Azu G.O
}

${ }^{1}$ Faculty of Sciences, Industrial Chemistry Department Ebonyi State University

Abakaliki, Nigeria.

${ }^{1 *}$ mirinkwa@gmail.com

${ }^{2}$ Faculty of Sciences, Industrial Chemistry Department Ebonyi State University

Abakaliki, Nigeria.

\begin{abstract}
This investigation dealt with the dyeing and fastness properties of crude constituents of Ixora coccinea and Hibiscus sabdarriffa plant species extracted using distilled water, methanol and chloroform. Approximately $150 \mathrm{~g}$ of each sample was soaked in the chosen solvent for four weeks, the percentage yields of the aqueous, methanol and chloroform extracts of Ixora coccinea were $38.47 \%$ and $13.40 \%$ and $3.88 \%$ respectively; Hibiscus sabdariffa gave yields of $22.85 \%$ for the aqueous extract, $12.24 \%$ for the methanol extract and $3.79 \%$ for the chloroform extract. Aqueous, methanol and chloroform extracts of Ixora coccinea were all pink in colour; Hibiscus sabdariffa gave red aqueous extract, red methanol extract and orange chloroform extract. The extracts were used without further purification in dyeing unmordanted and mordanted cotton and polyester fabrics. Different colour shades were obtained after dyeing. The mordanted fabrics using $\mathrm{CuSO}_{4}, \mathrm{FeSO}_{4}$ and $\mathrm{K}_{2} \mathrm{CrO}_{7}$ were fast to acid, alkali and washing.
\end{abstract}

Key words: dyeing, extract, fastness, mordant, solvent

Academic Discipline And Sub-Disciplines

Science

\section{SUBJECT CLASSIFICATION}

Chemistry

TYPE (METHOD/APPROACH)

Experimental

\section{Council for Innovative Research}

Peer Review Research Publishing System

Journal: Journal of Advances in Chemistry

\author{
Vol. 11, No. 5 \\ editorjaconline@gmail.com
}




\section{INTRODUCTION}

In the past all dyes, indicators and paint were obtained from nature- directly from animals such as lac, cochineal, kermes; from minerals such as various inorganic metal salts and metal oxides and plants such as roots, flowers, foliage, nuts, trunk, fruit, bark, berries etc(Anjali, Deepali, 2012; Buchanan, 1999).

With the present awareness all over the world of problem posed by synthetic compounds and dyes, natural dyes are gaining attention because of their non toxicity, safe handling and pose no environmental danger or hazard(Pathan and Mazahar, 2011; Adeel, Ali, Bhatti and Zsilla, 2009; Akpuaka, Chukwueneke and Agbo, 1998; Ferricira and Hulme, 1993. Ledakowicz, Olczyk, Polak, Graz and Wilkolazka 2015).

Dyes are intensely coloured substances which when applied to a substance, imparts colour to it by a process which at least temporarily destroys the crystal structure of the coloured substance. The dye must be attractive and capable of being fixed to the substrate directly or with the help of certain reagents called mordants. The dye must be colour fast, produced at a relatively low cost, cheap to obtain and readily available (Bhattacharya and Shah, 2000; Green, 1995; Bhuyan and Saika, 2004).

Hibiscus sabdariffa is an herbaceous and perennial plant cultivated in the tropical and sub tropical regions. It belongs to a family of plants called malvaceae of which over three hundred species have been described (Tease and Evans, 1995). In Africa especially Nigeria it is prepared as a non alcoholic beverage and is known as Zobo. The extract from Hibiscus sabdariffa is used in herbal medicine as antiseptic, aphrodisiac, astringent, cholagogue and demulcent. The extract from Ixora coccinea has been found to exhibit antioxidant, antibacterial, antidiarrhoeal, antimutagenic properties([Manjeshewar and Poruthukaran, 2012; Bhattacharjee, 1994).

The author decided to look at the use of these common plant species as local/natural dyes for fabrics and by extension their use in the dye industry; cosmetics, food and biology stains considering their medicinal and physiological uses.

\section{GENERAL EXPERIMENTAL PROCEDURES}

All reagents used were of analytical grade, purchased from BDH, England and Merck Germany. All weighing was done on Mettler P2100.

\subsection{Plant Samples}

Dry samples of Hibiscus sabdariffa (zobo) were purchased from Meat Market Abakaliki, Ebonyi State Nigeria in May 2014 while fresh samples of Ixora coccinea were handpicked from the office complex of Faculty of Science Ebonyi State University Abakaliki in June 2014 during the flowering season. Both samples were identified by the Applied Biology Department Faculty of Science Ebonyi State University.

\subsection{Sample Preparation}

Approximately $1000 \mathrm{~g}$ of each sample was washed with distilled water to remove sand and dirt and air dried for seven days. The dried samples were pulverized and stored in air tight cellophane until ready for use.

\subsection{Extraction}

About $150 \mathrm{~g}$ of Hibiscus sabdariffa was soaked in $500 \mathrm{~mL}$ of distilled water, methanol and chloroform respectively. The same $150 \mathrm{~g}$ of sample and procedure of soaking was carried out for Ixora coccinea. The soaked samples were allowed to stand for four weeks to achieve exhaustive extraction of the constituents of the plant species. Each sample solution was filtered and the filtrate evaporated to dryness by mild heating to reveal dark red Hibiscus sabdariffa aqueous extract (HSAE); red Hibiscus sabdariffa methanol extract (HSME); orange Hibiscus sabdariffa chloroform extract (HSCE); dark brown Ixora coccinea aqueous extract (ICAE); Purple Ixora coccinea methanol extract (ICME) and brown Ixora coccinea chloroform extract (ICCE) (Osabohien and Ukponmwan, 2002). The solubility of the extracts in distilled water and ethanol was determined.

\subsection{Preparation of Dye Baths}

About $0.4 \mathrm{~g}$ of HSAE, HSME, HSCE ICAE; ICME and ICCE were used in the preparation of six different dye baths. HSAE, HSME, ICAE; ICME and ICCE were dissolved in $100 \mathrm{~mL}$ of distilled hot water while $0.4 \mathrm{~g}$ of (HSCE) was first dissolved in

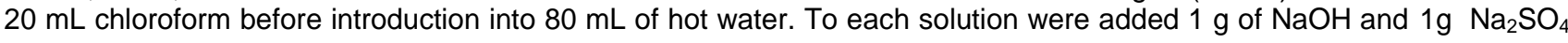
respectively and heated to a temperature of $45^{\circ} \mathrm{C}$ until a uniform mixture was obtained.

\subsection{Dyeing of Cotton and Polyester Fabrics}

About six pieces of $30 \times 30 \mathrm{~cm}$ of each of the white fabrics (cotton and polyester) were prepared by boiling in $10 \% \mathrm{NaOH}$ for $15 \mathrm{~min}$ to remove starch and other impurities and then introduced into each dye bath and the temperature was raised to $80^{\circ} \mathrm{C}$ and allowed to simmer at that temperature for $30 \mathrm{~min}$. The dye baths were removed from source of heat and allowed to cool to $40^{\circ} \mathrm{C}$ for $15 \mathrm{~min}$. The fabrics were removed without rinsing and allowed to dry at room temperature for 6 $\mathrm{h}$, the dried fabrics showed different colours. 


\subsection{Fastness Tests of unmordanted fabrics}

\subsubsection{Colour fastness to Acid}

Six pieces of each fabric $(5 \times 5 \mathrm{~cm}$ ) were dipped in $10 \% \mathrm{HCl}$ for $5 \mathrm{~min}$, removed without rinsing and allowed to dry at room temperature.

\subsubsection{Colour fastness to Alkali}

Six pieces of each fabric $(5 \times 5 \mathrm{~cm})$ were dipped in $10 \% \mathrm{NaOH}$ solution for $5 \mathrm{~min}$, removed without rinsing and allowed to dry at room temperature.

\subsubsection{Wash Fastness}

Six pieces of each fabric $(5 \times 5 \mathrm{~cm})$ were soaked in $10 \%$ soap solution for $6 \mathrm{~h}$, washed for $5 \mathrm{~min}$, rinsed in water and dried at room temperature (Baishya, Talukdah and Sandya, 2012).

\subsection{Mordanting and Dyeing of Fabrics}

Approximately $0.4 \mathrm{~g}$ of Ferrous sulphate, Copper sulphate and Ferric chloride and potassium dichromate were weighed out separately and dissolved in $100 \mathrm{~mL}$ of hot water respectively. To each salt were added $0.4 \mathrm{~g} \mathrm{Na}_{2} \mathrm{CO}_{3}$ and Na$_{2} \mathrm{SO}_{4}$ and allowed to simmer for $10 \mathrm{~min}$, cotton and polyester fabrics $5 \times 5 \mathrm{~cm}$ were each soaked separately in each metal salt solution for $45 \mathrm{~min}$ at a temperature $60^{\circ} \mathrm{C}$. The fabrics were removed and introduced into freshly prepared dye baths of HSAE, HSME. HSCE, ICAE, ICME and ICCE and the temperature of the baths gradually raised to $90^{\circ} \mathrm{C}$ and allowed to simmer for $1 \mathrm{~h}$. After $1 \mathrm{~h}$ the dye baths were allowed to cool for $20 \mathrm{~min}$, and the dyed fabrics removed and spread at room temperature until dry.

\subsubsection{Fastness Tests of unmordanted fabrics}

The same procedure was followed for the fastness tests of the mordanted fabrics.

\section{RESULTS}

Percentage yield of the extracts appears on Table I; the solubility of the extracts in water and ethanol is shown in Table II, the result of the dyeing of the unmordanted fabrics appears on Table III; fastness properties of the unmordanted fabrics is on table IV; colours of dyed Fabrics using different mordants is outlined on Table V; the fastness tests are shown on Tables VI, VII and VIII.

Table I Percentage Yield of the Extracts

\begin{tabular}{|c|c|c|c|}
\hline Extracts & Weight of Plant Powder(g) & Weight of dye & Percentage yield (\%) \\
\hline HSAE & 150 & 34.28 & 22.85 \\
\hline HSME & 150 & 24.47 & 12.24 \\
\hline HSCE & 150 & 5.68 & 3.79 \\
\hline ICAE & 150 & 57.71 & 38.47 \\
\hline ICME & 150 & 20.10 & 13.40 \\
\hline ICCE & 150 & 5.82 & 3.88 \\
\hline
\end{tabular}

Table II Solubility of HSAE, HSME, HSCE ICAE; ICME and ICCE in Water and Ethanol

\begin{tabular}{|c|cc|}
\hline Extract & \multicolumn{2}{|c|}{ Solvent } \\
& Distilled water & ethanol \\
\hline HSAE & soluble & soluble \\
\hline HSME & insoluble & insoluble \\
\hline HSCE & soluble & soluble \\
\hline ICAE & soluble & insoluble \\
\hline ICME & soluble & soluble \\
\hline ICCE & soluble & soluble \\
\hline
\end{tabular}




\section{ISSN 2321-807X}

Table III Colours of the Dyed unmordanted Fabrics

\begin{tabular}{|c|cc|}
\hline Extract & \multicolumn{2}{|c|}{ Colour on fabrics } \\
& Cotton & Polyester \\
\hline HSAE & red & pink \\
\hline HSME & light green & red \\
\hline HSCE & pink & light yellow \\
\hline ICAE & red & violet \\
\hline ICME & red & light brown \\
\hline ICCE & light red & \\
\hline
\end{tabular}

Table IV Fastness properties of the unmordanted fabrics

\begin{tabular}{|c|c|c|c|c|c|c|}
\hline \multirow{2}{*}{ Extract } & & Cotton & & \multicolumn{3}{|c|}{ Polyester } \\
\hline & acid & alkali & wash & acid & alkali & wash \\
\hline HSAE & 3 & 4 & 3 & 4 & 3 & 4 \\
\hline HSME & 3 & 4 & 3 & 4 & 3 & 4 \\
\hline HSCE & 4 & 3 & 4 & 4 & 4 & 3 \\
\hline ICAE & 3 & 4 & 3 & 4 & 3 & 3 \\
\hline ICME & 4 & 4 & 4 & 3 & 3 & 4 \\
\hline ICCE & 4 & 4 & 4 & 4 & 4 & 4 \\
\hline
\end{tabular}

3 = slightly fast; 4 = not fast

Table IV Colours of Mordanted Dyed Fabrics

\begin{tabular}{|c|c|c|c|c|c|c|c|c|}
\hline \multirow[t]{2}{*}{ Extracts } & \multicolumn{4}{|c|}{ Colours of Mordants on Cotton } & \multicolumn{4}{|c|}{ Colours of Mordants on Polyester } \\
\hline & $\mathrm{CuSO}_{4}$ & $\mathrm{FeSO}_{4}$ & $\mathrm{FeCl}_{3}$ & $\mathrm{~K}_{2} \mathrm{CrO}_{7}$ & $\mathrm{CuSO}_{4}$ & $\mathrm{FeSO}_{4}$ & $\mathrm{FeCl}_{3}$ & $\mathrm{~K}_{2} \mathrm{CrO}_{7}$ \\
\hline HSAE & White & Brown & Orange & Yellow & White & Brown & Orange & Pink \\
\hline HSME & Grey & Brown & Yellow & Orange & Grey & Brown & Yellow & Pink \\
\hline HSCE & Green & Orange & Grey & Yellow & Green & Orange & Grey & Yellow \\
\hline ICAE & Pink & Brown & Orange & Red & Pink & Brown & Orange & Red \\
\hline ICME & Pink & Brown & Pink & Orange & Pink & Brown & Pink & Orange \\
\hline ICCE & white & brown & brown & violet & white & brown & brown & pink \\
\hline
\end{tabular}


Table V Acid Fastness of the mordanted Dyed fabrics

\begin{tabular}{|c|c|c|c|c|c|c|c|c|}
\hline \multirow[t]{2}{*}{ Extracts } & \multicolumn{4}{|c|}{ Colours of Mordants on Cotton } & \multicolumn{4}{|c|}{ Colours of Mordants on Polyester } \\
\hline & $\mathrm{CuSO}_{4}$ & $\mathrm{FeSO}_{4}$ & $\mathrm{FeCl}_{3}$ & $\mathrm{~K}_{2} \mathrm{CrO}_{7}$ & $\mathrm{CuSO}_{4}$ & $\mathrm{FeSO}_{4}$ & $\mathrm{FeCl}_{3}$ & $\mathrm{~K}_{2} \mathrm{CrO}_{7}$ \\
\hline HSAE & 2 & 1 & 1 & 1 & 3 & 2 & 2 & 1 \\
\hline HSME & 2 & 2 & 1 & 1 & 3 & 1 & 1 & 1 \\
\hline HSCE & 1 & 1 & 2 & 2 & 1 & 2 & 1 & 1 \\
\hline ICAE & 1 & 1 & 2 & 2 & 1 & 2 & 1 & 2 \\
\hline ICME & 1 & 2 & 1 & 1 & 2 & 1 & 2 & 1 \\
\hline ICCE & 2 & 2 & 4 & 4 & 2 & 4 & 4 & 4 \\
\hline
\end{tabular}

1 = very fast; 2 = fast; 3 = slightly fast; 4 = not fast

Table VI Alkaline Fastness of the mordanted Dyed fabrics

\begin{tabular}{|c|c|c|c|c|c|c|c|c|}
\hline \multirow[t]{2}{*}{ Extracts } & \multicolumn{4}{|c|}{ Colours of Mordants on Cotton } & \multicolumn{4}{|c|}{ Colours of Mordants on Polyester } \\
\hline & $\mathrm{CuSO}_{4}$ & $\mathrm{FeSO}_{4}$ & $\mathrm{FeCl}_{3}$ & $\mathrm{~K}_{2} \mathrm{CrO}_{7}$ & $\mathrm{CuSO}_{4}$ & $\mathrm{FeSO}_{4}$ & $\mathrm{FeCl}_{3}$ & $\mathrm{~K}_{2} \mathrm{CrO}_{7}$ \\
\hline HSAE & 2 & 1 & 1 & 1 & 2 & 2 & 1 & 1 \\
\hline HSME & 1 & 1 & 2 & 1 & 2 & 1 & 2 & 2 \\
\hline HSCE & 2 & 1 & 2 & 2 & 1 & 1 & 2 & 2 \\
\hline ICAE & 1 & 1 & 2 & 1 & 1 & 2 & 1 & 2 \\
\hline ICME & 1 & 2 & 1 & 1 & 2 & 2 & 1 & 2 \\
\hline ICCE & 3 & 1 & 4 & 4 & 4 & 1 & 4 & 3 \\
\hline
\end{tabular}

$1=$ very fast; 2 = fast; 3 = slightly fast; 4 = not fast

Table VII Wash Fastness of the mordanted Dyed fabrics

\begin{tabular}{|c|c|c|c|c|c|c|c|c|}
\hline \multirow[t]{2}{*}{ Extracts } & \multicolumn{4}{|c|}{ Colours of Mordants on Cotton } & \multicolumn{4}{|c|}{ Colours of Mordants on Polyester } \\
\hline & $\mathrm{CuSO}_{4}$ & $\mathrm{FeSO}_{4}$ & $\mathrm{FeCl}_{3}$ & $\mathrm{~K}_{2} \mathrm{CrO}_{7}$ & $\mathrm{CuSO}_{4}$ & $\mathrm{FeSO}_{4}$ & $\mathrm{FeCl}_{3}$ & $\mathrm{~K}_{2} \mathrm{CrO}_{7}$ \\
\hline HSAE & 2 & 1 & 1 & 1 & 2 & 4 & 1 & 1 \\
\hline HSME & 1 & 1 & 2 & 1 & 2 & 1 & 2 & 1 \\
\hline HSCE & 2 & 1 & 2 & 2 & 1 & 2 & 2 & 2 \\
\hline ICAE & 1 & 1 & 1 & 1 & 1 & 1 & 1 & 2 \\
\hline ICME & 1 & 2 & 1 & 1 & 2 & 2 & 1 & 1 \\
\hline ICCE & 3 & 1 & 4 & 4 & 2 & 1 & 4 & 4 \\
\hline
\end{tabular}

1 = very fast; 2 = fast; 3 = slightly fast; 4 = not fast 


\section{DISCUSSION}

The powdered plant species after extraction in the three different solvents gave the highest yield using water; $22.85 \%$ HSAE and $38.47 \%$ ICAE. The methanol extract of the plant materials gave $12.24 \%$ for HSME and $13.40 \%$ for ICAE. The yield using chloroform was low; $3.79 \%$ HSCE and $3.88 \%$ ICCE. The implication of the result obtained using chloroform was that chloroform was not a good solvent to use for the extraction of the constituents of these plant materials.

The extracts were appreciably soluble in water except HSME and in ethanol except HSME and ICAE. All the extracts gave colours ranging from red, green, pink, yellow and brown on unmordanted cotton and polyester fabrics. The acid, alkaline and wash fastness of the unmordanted fabrics was poor.

Fresh white cotton and polyester fabrics were treated with metal salts $\mathrm{CuSO}_{4}, \mathrm{FeSO}_{4}, \mathrm{FeCl}_{3}$ and $\mathrm{K}_{2} \mathrm{CrO}_{7}$ as mordants and dyed to help to make the colours able to be fixed on the fabrics. It was observed that the use of mordants gave different colours from the ones obtained without the use of the metal salts. HSAE, HSME, HSCE, ICAE, ICME and ICCE gave colours that vary from white, brown, orange, yellow and pink using $\mathrm{CuSO}_{4}, \mathrm{FeSO}, \mathrm{FeCl}_{3}$ and $\mathrm{K}_{2} \mathrm{CrO}_{7}$ on the two fabrics used. That is different shades were obtained from a single extract, using different mordants.

Cotton and polyester mordanted fabrics when dyed with HSAE, HSME, ICAE and ICME and treated with $10 \% \mathrm{HCl}$, showed excellent fastness property except HSAE and HSME which gave poor result with polyester mordanted with $\mathrm{CuSO}_{4}$ and also ICCE which gave poor result with $\mathrm{FeCl}_{3}$ and $\mathrm{K}_{2} \mathrm{CrO}_{7}$ mordanted cotton and $\mathrm{FeCl}_{3}$ and $\mathrm{FeSO}_{4}$ mordanted polyester.

The mordanted dyed fabrics were all fast to $10 \%$ alkali except ICCE on cotton mordanted with $\mathrm{CuSO}_{4}, \mathrm{FeCl}_{3}$ and $\mathrm{K}_{2} \mathrm{CrO}_{7}$ and ICCE on polyester mordanted with $\mathrm{CuSO}_{4}, \mathrm{FeCl}_{3}$ and $\mathrm{K}_{2} \mathrm{CrO}_{7}$.

All the mordanted dyed fabrics were fast to washing except ICCE which was only wash fast on FeSO4 mordanted cotton and polyester.

The results of the investigation showed that Hibiscus sabdariffa and Ixora coccinea extracts could be used in dyeing fabrics as a source of natural dyes for natural and synthetic fibers. Though used as beverage in the case of Hibiscus sabdariffa the plant material could be of immense help in the dye industry especially the aqueous extract for cosmetics. It could also find use in the food and drug industries. The methanol extract could be used in paints and other materials that are non-edible. The colour exhibited by the unmordanted and mordanted dyed fabrics, acid, alkali and wash fastness showed that these plant dyes have affinity and showed acceptable fastness properties.

\section{REFERENCES}

[1] Anjali, A., Deepali, R. 2012. Dyeing parameters of hydroxynaphthoquinone extracted from arnebia nobillis Rech. F. Ind. J. Fibers and Textiles Res. 37, 91-97.

[2] Buchanan, R. 1999. A weavers Garden; Growing Plants for Natural Dyes and Fibers. Dover Ed. Watson-Gupta Publications, $\mathrm{P} 230$.

[3] Pathan, M, Mazahar, F. 2011. Analytical application of plants extract as natural pH indicators: A Review, J. Sci. Res. 2(4), 20-27.

[4] Adeel, S; Ali, S; Bhatti, J and Zsilla, F. 2009. Dyeing of cotton fabric using pomegranate(punica granatum) aqueous extract. Asian J. Chem. 21(5), 3493-3499.

[5] Akpuaka, M.U;Chukwueneke, C. and Agbo, G.1998. The dyeing of textile fabrics with natural dyes from some local trees. J. Chem. Soc. Nigeria, 2(3), 47.

[6] Ferricira, E.S, Hulme, A.N 1993. The natural constituents of historical textile dyes. Chem.Soc. Rev. 33, 329.

[7] Bhattacharya, S.d, Shah, A.K. 2000. J. Soc. of Dyers and Chem, 116,10.

[8] Green, C.I, 1995. Nutritional colourant and dye stuff; A review of production markets and development potential. Food and Agricultural Organization, United Nations, Rome, 1-34.

[9] Bhuyan, R; Saika, C.N 2004. Isolation of colour components from native dye bearing plants in north eastern india. Am. J. of path.164(5), 873-877.

[10] Manjeshewar, S.B, Poruthukaran, J.K. 2012. Chinese J. of Intregative Med. 18(1), 72-79.

[11] Trease, G.E. and Evans, W.C. 1995 . A Textbook of Pharmacognosy, W.B.Sauders, London, 201.

[12] Ledakowicz, J.S; Olczyk, J; Polak, J; Graz, M. and Wilkolazka, A. 2015. Dyeing of textile fabrics with bio-dyes. Fibers and Textiles in Eastern Europe, 23, 1 (109), 120-126. 
[13] Bhattacharjee S.K. 1994.. Handbook of Medicinal Plants, $3^{\text {rd }}$. Edition Pointer Publishers (P) Ltd, New Delhi, P239.

[14] Baishya,D; Talukdah, J and Sandya, S. 2012. Cotton dyeing with natural dyes extracted from flower of bottlebrush(Callistemon Citrinus), Univer. J. Environ. Res. and Tech. 2 (5), 377-382.

[15] Osabohien, E and Ukponmwan, D.O.2002. Extraction of natural dyes from some local plants, J. of Chem.ical Soc. Of Nigeria, 27 (2), 139-140.

\section{Author's biography with Photo}

Dr.(Mrs) Nwokonkwo, D.C. is a well known Senior Lecturer in Organic/Natural Product Chemistry and holds a Ph.D in Organic Chemistry. She has to her credit twenty- four years teaching experience at undergraduate and postgraduate levels of Faculty of Science, Department of Natural and Applied Chemistry University of Portharcourt Nigeria and Industrial Chemistry Department, Faculty of Science Ebonyi State University Abakaliki, Nigeria. She has over thirty articles and books to her credit.

She is a member of the Institute of Chartered Chemists of Nigeria(ICCON) and Chemical Society of Nigeria (CSN).

She has worked as a Quality Control Manager in a pharmaceutical company El-Shaddai Pharmaceutical Company Limited in Enugu State of Nigeria. She is married with children. 